\title{
Physics, Pharmacology and Physiology for Anaesthetists Key Concepts for the FRCA
}

\author{
Matthew E. Cross, Emma V.E. Plunkett. Cambridge University Press, 2008, \\ 268 pp, \$58.95 CAN, ISBN 978-0-521-70044-3
}

\author{
Sanjiv Gupta, MD
}

Published online: 28 January 2009

(C) Canadian Anesthesiologists' Society 2009

It is clear from reading the preface and foreword of this book that it is intended as a study guide for the FRCA (Great Britain) examination. This paperback includes ten sections that can be divided into four major categories: mathematics and physics (80 pages), pharmacology (40 pages), physiology (80 pages), and statistics (20 pages). The concepts described in each chapter are accompanied by succinct definitions and well-labelled diagrams; yet, the book is not referenced and there are no suggestions for in-depth reading.

The authors made an impressive effort to present the concepts in the mathematics and physics section in a clinically relevant manner. For example, they present the principles of capacitors and inductors in the context of a defibrillator circuit. It would have been useful had they continued in the same vein throughout the book.

In the pharmacology section, the authors use actual drug names to explain only two concepts, concentration effect and context sensitive half time. Most of the remaining topics are depicted using graphs where the curves are simply labelled drug A, B, or C. Use of additional clinical examples would have helped trainees grasp the material more effectively.
The physiology section covers important principles in cardio-respiratory, renal, and neurophysiology. The detail in this section is appropriate for a book which is meant to provide a quick review. The chapters on statistics cover many principles that may not be relevant for the FRCPC (Canadian) examination, but are important to understand. The text is clear and concise, and good use is made of tables and graphs to illustrate concepts that many trainees may find confusing.

In his review of this book in the November 2008 issue of the British Journal of Anaesthesia, the author compared it to Basic Science for Anaesthetists by Sylva Dolenska. A review of Basic Science for Anaesthetists appears in the March 2007 issue of the Canadian Journal of Anesthesia.

Physics, Pharmacology and Physiology for Anaesthetists does a better job than most texts of this sort in presenting mathematics and physics principles in a clinical context. The book could also function as a portable resource for attending anesthesiologists who are interested in helping trainees prepare for the FRCPC examination. It would make for a much more engaging read if the authors had made a more consistent effort throughout the text to present why basic science concepts are clinically important.

S. Gupta, MD ( $\square)$

The Ottawa Hospital, University of Ottawa, Ottawa, Canada

e-mail: sgupta@alumni.uottawa.ca 